\title{
ANÁLISE CLÍNICA E HISTOLÓGICA DA UTILIZAÇÃO DA RESINA ACRÍLICA AUTOPOLIMERIZÁVEL NAS FRATURAS DE MANDÍBULA E MAXILA E SEPARAÇÃO DA SÍNFISE MENTONIANA EM CÃES E GATOS.
}

\author{
CLINICAL AND HISTOLOGICAL EVALUATION OF ACRYLIC RESIN IN THE \\ FRACTURE OF THE MANDIBLE AND MAXILLA AND SEPARATION OF \\ MANDIBULAR SYMPHISIS IN DOGS AND CATS
}

\author{
Marco Antonio Gioso ${ }^{1}$ Regina Suplicy Vianna ${ }^{2}$ Michèle Alice Françoise Anita Venturini ${ }^{3}$ \\ Herbert Lima Correa ${ }^{3}$ Alexandre Venceslau ${ }^{4}$ Vera Cavalcanti Araújo ${ }^{5}$
}

RESUMO

O trabalho foi desenvolvido em duas fases. A primeira constou de aplicação de resina acrílica autopolimerizável sobre dentes de cães experimentais, sem condicionamento ácido do esmalte dental; a gengiva foi analisada histologicamente nos períodos de um, três, sete, 14, 21 e 30 dias. A segunda fase foi conduzida em 20 cães e 10 gatos com fraturas do sistema estomatognático, atendidos no Ambulatório Central da FMVZ/USP. Nessa segunda fase, clínica, foi aplicado condicionamento ácido do esmalte. A resina era usada nas fraturas rostrais às raízes distais do primeiro molar inferior e do quarto pré-molar superior, bem como na separação da sínfise mentoniana. Os resultados da primeira fase mostraram que mesmo sem o condicionamento ácido houve aderência da resina acrílica sobre os dentes, embora houvesse necessidade de maior volume do material, o que provocou ulcerações dos tecidos moles da boca. Essa fase também evidenciou, à sondagem, que o epitélio de aderência sulcular permaneceu aderido, além de gengivite, ulceração da gengiva, língua e mucosa alveolar. A análise histológica revelou predominantemente ulceração dos tecidos em contato com a resina. $\mathrm{Na}$ segunda fase, todos os animais evidenciaram consolidação óssea das fraturas, além de gengivite e ulceração. Lesões periodontais foram encontradas em dois animais dos quais a resina foi removida tardiamente, com quatro e 12 meses após a aplicação, respectivamente. Em ambas as fases, os animais adaptaram-se bem à resina sobre os dentes.

Palavras-chave: resina acrílica, fratura, mandíbula, maxila, cão, gato.
SUMMARY

This paper was performed in two phases. In the first one, the stability of the acrylic resin over the teeth of dogs, without enamel acid conditioning, the clinical and histological reaction on the gingiva were analyzed in periods of 1, 3, 7, 14, 21 and 30 days. The second phase was conducted in 20 dogs and 10 cats, with acid etching technique. The resin was used in the rostral fractures to the distal roots of the lower first molar and upper fourth premolar, as well as in the separation of the symphisis. The results of the first phase indicated that even without the acid etching technique, the acrylic resin remained fixed over the teeth, although a higher volume of resin was needed, thus inducing more areas of ulceration on the lips, gingiva and tongue. This phase also demonstrated that the sulcular gingival adhesion epithelium remained attached to the teeth. Gingivitis, ulceration on the gingiva, tongue and alveolar mucosa were also observed. The histologic analyses mainly showed ulceration of the gingival epithelium. In the second phase all animals featured clinical bone healing in the site of fracture, as well as gingivitis and ulceration. Periodontitis was found in two animals whose resin was not removed up to four and twelve months after application of the acrylic resin. The results also showed that the method can be used in fractures rostral to the distal roots of upper fourth pre-molar an first lower molar.

Key words: acrylic resin, fracture, mandible, maxilla, dog, cat.

\footnotetext{
${ }^{1}$ Médico Veterinário, Professor Assistente do Departamento de Cirurgia da Faculdade de Medicina Veterinária e Zootecnia (FMVZ) da Universidade de São Paulo (USP). Av. Professor Doutor Orlando Marques de Paiva, 87, Cidade Universitária, 05508-900, São Paulo, SP, Brasil. E-mail: maggioso@usp.br. Autor para correspondência.

${ }^{2}$ Pós-graduando (doutorado) em Anatomia da FMVZ/USP. Professor de Anatomia da UNIBAN, SP.

${ }^{3}$ Médicos Veterinários do Odontovet, Centro Odontológico Veterinário, SP

${ }^{4}$ Acadêmico de Veterinária da FMVZ/USP. Bolsista da FAPESP.

${ }^{5}$ Professor Titular do Departamento de Estomatologia da Faculdade de Odontologia da USP
} Recebido para publicação em 26.11.99. Aprovado em 05.07.00 


\section{INTRODUÇÃO}

Os princípios básicos da reparação de fraturas dos ossos maxilar, incisivo e da mandíbula, bem como a separação da sínfise mentoniana devem, segundo MARRETA et al. (1990), obedecer aos seguintes fatores para que se estabeleça a consolidação óssea perfeita: alinhamento oclusal, estabilidade adequada, ausência de danos em tecidos moles e duros, preservação da dentição e retorno imediato à função.

Pela compilação da literatura, denota-se que a grande variedade de métodos de fixação de fraturas dos ossos maxilar, incisivo e da mandíbula, e separação da sínfise mentoniana, nem sempre atendem aos princípios mencionados, especialmente no que se referem as alterações dos tecidos moles e duros da região (THOLEN, 1983; DAUTHEVILLE \& BARRAIRON, 1985; EISENMEMGER \& ZETNER, 1985; BOJRAB, 1991). A resina acrílica autopolimerizável (polimetilmetacrilato) possibilita a obtenção dos princípios citados, além de fácil aplicação, aquisição e baixo custo (COLAHAN \& PASCOE, 1983; MULLIGAN, 1989). LUSKIN (1994) refere que o uso do acrílico em Odontologia Veterinária ganhou muita popularidade devido ao seu fácil manuseio e diversidade de utilização.

HARVEY et al. (1990) indicam para a disjunção da sínfise, a passagem de fios de aço pelos tecidos moles na região dos caninos, entre o osso e a pele, cerclando a mandíbula. $\mathrm{Na}$ maxila, a maioria das fraturas requer apenas tratamento conservador. ZETNER (1985) indica o uso de pinos metálicos na coroa dos caninos superiores e inferiores como forma de retenção para resina composta, a fim de estabilizar a oclusão nas fraturas de mandíbula dos felinos. McOWEN (1987) relata um caso de fratura entre o segundo e terceiro pré-molar inferior em cão, para a qual realizou moldagem e preparou uma placa de resina acrílica sobre o modelo construído, e, posteriormente, levou à boca do animal, além de utilizar fio de aço, colar protetor e antibiótico. KANGUR $\boldsymbol{e t}$ al. (1976), trabalhando com fraturas em cães experimentais, relatam o uso de metilmetacrilato implantado no foco de fratura, entre os fragmentos, por meio de acesso intra-oral, obtendo bons resultados quanto à estabilidade do foco de fratura.

HOLMSTROM et al. (1992) indicam a resina acrílica após condicionamento ácido nas fraturas rostrais ao primeiro molar inferior, nas fraturas complexas maxilo-faciais, mesmo em casos de dentes luxados ou subluxados e para aumento de estabilidade de outras técnicas. Como complicações de seu uso, relatam: exotermia, levando à ulceração de tecidos moles, a qual pode ser minimizada pela irrigação com água; escorrimento do material para os tecidos moles, impedindo a cicatrização; excesso de resina que leva à ulceração da mucosa, a qual, segundo os autores, resolve-se em poucos dias. Também indicam usar o método indireto, além de fio de aço para cerclagem na separação de sínfise. WIGGS \& LOBPRISE (1997) descrevem diferentes técnicas de cerclagem nos dentes, embora digam que os fios podem afrouxar, causando irritação e retração gengival, pela fixação nem sempre adequada nas fraturas instáveis.

Objetivou-se estudar a eficácia da aderência da resina acrílica sobre dentes não condicionados e estudar a reação gengival a ela (fase experimental), bem como o aspecto clínico de sua utilização em casos de fraturas (fase clínica).

\section{MATERIAL E MÉTODOS}

O presente trabalho foi realizado em duas fases. Na primeira, experimental em cães, não foi aplicado condicionamento ácido no esmalte. A segunda fase, clínica, foi realizada em cães e gatos atendidos no HOVET da FMVZ-USP de março de 1991 a agosto de 1994, na qual procedeu-se ao condicionamento ácido do esmalte dental. Em ambos os métodos, a resina acrílica foi misturada em pote de vidro e aplicada com os dedos na fase plástica da reação da polimerização.

\section{Fase Experimental}

Foram utilizados seis cães, sem raça definida, com peso médio de $10 \mathrm{~kg}$ e idade desconhecida, uma vez que provinham do Canil Central da FMVZUSP. Os cães apresentavam-se clinicamente sadios, o que foi avaliado por exame clínico, bioquímica sérica, hemograma e nível sérico de uréia e creatinina. Todavia, pelas características físicas e análise da dentição, os cães apresentavam, provavelmente, entre dois e três anos de idade (GIOSO, 1994).

Todos os animais foram anestesiados com pentobarbital sódico a 3\%. Procedeu-se ao exame da cavidade bucal com explorador e sonda periodontal. Foram escolhidos para o experimento cães sem evidentes sinais clínicos, por inspeção visual direta, de gengivite em grau médio ou avançado (sangramento espontâneo, edema, eritema) ou periodontite (retração gengival, exposição de furca, presença de cálculo em grande quantidade). Todavia, foram aceitos cães com grau leve de placa e cálculo dental. A profundidade máxima do sulco gengival de todos os dentes utilizados foi de dois milímetros. Todos os dentes tiveram a placa e o cálculo dental removidos com extratores de cálculo manuais e curetas periodontais. Os dentes foram, então, lavados com água 
e secos com ar proveniente de seringa hipodérmica, impulsionado pelo êmbolo. Não se procedeu à fratura de mandíbula em nenhum cão.

A resina acrílica ${ }^{a}$ foi então preparada pelo método de saturação entre o monômero e o polímero em um pote de vidro. Não foi aplicado condicionamento ácido sobre o esmalte. A resina foi recolhida do recipiente na fase plástica da reação e aplicada sobre os dentes da mandíbula direita por pressão digital. O lado esquerdo foi utilizado como controle, não recebendo a massa resinosa.

A resina cobriu desde o segundo molar inferior até o canino isolateral. Nas áreas de retenção anatômica, tanto em nível de coroa quanto interdentais, houve o cuidado de proceder a seu preenchimento por meio de pressão com um instrumento de ponta romba, como o cabo espelho clínico, a fim de aumentar a retenção, havendo contato da resina com a gengiva. Durante a fase plástica de polimerização, a boca foi fechada passivamente, a fim de que a oclusão pudesse ser a mais próxima do normal, com a resina entre o arco superior e inferior, sendo marcada pelos dentes em oclusão. $O$ calor da reação exotérmica da resina não foi minimizado.

Os cães foram alojados no canil central da FMVZ-USP e observados por até 5 horas de póscirúrgico imediato e de maneira regular até a data de sacrifício. Não houve higienização bucal no pósoperatório. A dieta consistiu de ração comercial ${ }^{\mathrm{b}} \mathrm{e}$ água. Esse procedimento foi aplicado em seis cães, sendo os mesmos sacrificados em um, três, sete, 14, 21 e 31 dias. Antes do sacrifício, após intervenção cirúrgica experimental em abdome, a resina foi removida com auxílio de fórceps odontológico universal e instrumentos cortantes rotatórios, sem lesar os tecidos moles. Toda a cavidade bucal foi reavaliada e os dados colhidos e cadastrados. O sulco gengival foi novamente medido na sua profundidade. A gengiva foi então descolada do leito ósseo, com o auxílio de um sindesmótomo e elevador periostal, da região dos incisivos ao último molar vestibular e lingualmente, e colocada em solução de formol a $10 \%$ para posterior análise histológica pelo método de Hematoxila-Eosina.

\section{Fase Clínica}

Uma vez comprovada a eficiência do uso da resina acrílica na fase experimental, no tocante a sua permanência na cavidade oral, a mesma foi utilizada em 20 cães e 10 gatos que foram apresentados ao ambulatório da disciplina de Técnica Cirúrgica da FMVZ-USP, de 1991 a 1994. Foram escolhidos para o experimento apenas separação de sínfise mentoniana e fraturas de mandíbula e maxila rostrais ao primeiro molar inferior ou ao quarto pré-molar supe- rior. A idade dos animais variou de 10 meses a 14 anos de idade. O peso variou de 1 a $60 \mathrm{~kg}$. A maior parte dos animais não tinha raça definida.

As fraturas que acometiam esses animais variaram de fraturas simples, sem exposição de tecido ósseo, unilaterais ou bilaterais em um ou ambos os arcos dentais. Também houve casos de fraturas expostas, tanto no arco superior, como no inferior, além de associação das fraturas citadas.

Três animais (dois cães e um gato) foram encaminhados ao HOVET com fraturas patológicas de mandíbula, na região do primeiro molar inferior. Pelo exame, constatou-se que as fraturas decorreram de reabsorção óssea por doença periodontal avançada. Nos três casos, a raiz mesial do dente primeiro molar inferior encontrava-se sem a estrutura periodontal completa, isto é, estava exposta exatamente no foco de fratura. Como as raízes distais encontravam-se sem ou com pouca mobilidade, esses dentes foram preservados, a fim de servir como retenção para a aplicação da resina. Em casos de avulsão de dentes e fraturas dentais, tentou-se preservá-los para que a resina pudesse ser fixada. Os dentes quase ou totalmente avulsionados não foram reimplantados.

Nas fraturas expostas, foram curetados os ossos, e os tecidos moles adjacentes. Nesses casos, os dentes eram raspados vigorosamente, incluindo as raízes, fosse essa exposição provocada pelo processo traumático ou por doença periodontal. Procedeu-se ao polimento dental com taça de borracha e pedrapomes. A cavidade bucal foi irrigada com solução de hipoclorito de sódio a 0,5\% (líquido de Dakin).

Os tecidos moles, caso lacerados, eram suturados com fio de poliglactina $910^{\mathrm{c}}$ número 2-0, 3-0 ou 4-0 dependendo do porte do animal, em pontos simples separados.

Os dentes foram lavados e secos com auxílio de gaze e seringa hipodérmica e a técnica de condicionamento ácido aplicada sobre os dentes utilizados como fixação. Essa técnica consiste na aplicação de solução de ácido ortofosfórico sobre a superfície dos dentes durante 15 segundos, e tem como finalidade promover a formação de microporos nos mesmos, visando à melhor aderência da resina (GIOSO et al., 1995). A massa resinosa foi aplicada sobre os dentes na fase plástica da reação, evitando-se contato com a gengiva, enquanto os fragmentos ósseos foram levados em posição anatômica, até a polimerização completa da resina. Da mesma forma que para os casos experimentais, a boca foi fechada, após extubação, para imprimir a oclusão sobre a massa resinosa durante a fase plástica (Figura 1). Em vista dos resultados histológicos obtidos na fase experimental, durante a polimerização da resina, foram aplicadas compressas de gaze 


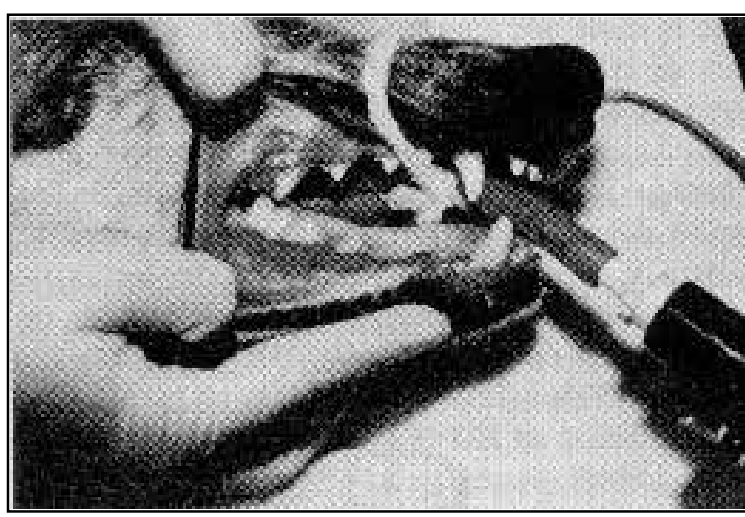

Figura 1 - Resina acrílica já colocada, após condicionamento ácido do esmalte, sobre todos os dentes da mandíbula com fratura completa do ramo direito, distal ao canino, antes da extubação para oclusão (note que a resina recobre todos os dentes inferiores, incluindo os incisivos). Cão sem raça definida, 3 anos de idade.

ou algodão com água para absorver o calor gerado na reação exotérmica.

Os proprietários foram instruídos a retornar após sete, 15 e 28 dias, para avaliação clínica e possível remoção da resina em 30 dias. Todas as mandíbulas e maxilas dos animais foram radiografadas previamente à remoção da massa resinosa.

\section{RESULTADOS}

\section{Fase Experimental}

Nenhum cão apresentou sinais evidentes de dor durante o período pós-operatório, embora, na primeira semana, tentassem remover a resina com as patas ou pela mastigação em objetos duros. Esse sinal foi diminuindo a partir da primeira semana, evidenciando que os animais se habituaram à massa resinosa. Não houve sinais de anorexia após a aplicação da resina, sendo que os animais utilizavam ambos os lados para mastigar o alimento, que consistiu em ração peletizada comercial. Todos os seis animais $(100 \%)$ do grupo experimental comeram a ração no máximo cinco horas após o retorno completo da anestesia.

Quando da remoção da resina, após sacrifício dos animais, evidenciaram-se em todos os cães sinais de halitose e gengivite. No entanto, não houve sinais de periodontite ao exame clínico. Pela exploração do sulco gengival, com explorador e sonda periodontal, não se observou perda de aderência do epitélio juncional. Em todos os cães, houve hemorragia gengival após exploração com a sonda periodontal. Nos cães de três, sete, 14, 21 e 31 dias, houve hemorragia gengival espontânea e grave edema e eritema gengival, que se agravaram nos cães de 14 , 21 e 31 dias, constatado pelo aumento da hemorragia e eritema. O sulco gengival apresentou-se com a profundidade aumentada (máximo de $2 \mathrm{~mm}$ de incremento), devido ao edema gengival, junto a alguns dentes (pseudo-bolsa). Ao exame visual, a mucosa jugal adjacente à massa resinosa e a face lateral da língua apresentaram lesões ulcerativas em pontos isolados.

A partir do cão do dia 3, isto é, dos cães dos dias três, sete, 14, 21 e 31 dias, houve aumento da halitose. Um grande acúmulo de placa foi observado aderido à face interna da resina, principalmente aquela em contato com a gengiva, após sua remoção, com odor pútrido nos cães de três, sete, 14, 21 e 31 dias.

Durante o descolamento da gengiva do leito ósseo mandibular para a análise histológica, notou-se intensa friabilidade do tecido, principalmente nos cães dos dias 14, 21 e 31 dias. Nesse momento, também se pôde avaliar clinicamente que o epitélio juncional estava ainda aderido aos dentes utilizados como retenção, como pôde ser comparado pela desinserção dificultosa também do lado controle. Alguns pontos isolados de ulceração foram notados na mucosa jugal e lingual, os quais foram colhidos para análise histológica. Nenhuma anormalidade foi observada do lado controle.

\section{Fase Clínica}

Os proprietários informaram que 15 cães e três gatos ingeriram alimentos e água no mesmo dia da intervenção cirúrgica (máximo de 6 horas após o final da cirurgia). Apenas um cão (3\% entre os 30 animais), Pastor Alemão, adulto, quebrou a massa resinosa no pós-operatório, após 1 semana de sua aplicação. O cão foi novamente anestesiado, quando se notou uma região adelgaçada no foco de fratura da resina, e o ponto de rompimento foi reconstruído com nova porção de resina. Dos 30 casos, 28 (93\% entre os 30 animais) tiveram a resina removida entre 28 e 35 dias, independentemente dos resultados radiográficos. Após a remoção da resina, não houve sinais de mobilidade ou crepitação no foco de fratura, embora não houvesse sinais radiográficos de consolidação óssea em 12 cães e 7 gatos (63\% dos 30 animais) (Figura 2). Um felino, sem raça definida (3\% entre os 30 animais), com fratura patológica da mandíbula teve a resina removida após 4 meses, uma vez que o proprietário retornou apenas após esse período. Houve hemorragia gengival sob a resina, halitose intensa e dor à palpação, caracterizando periodontite. À remoção da massa resinosa, o quarto pré-molar inferior mostrava-se com grande mobilidade no alvéolo, sendo assim extraído facilmente. 


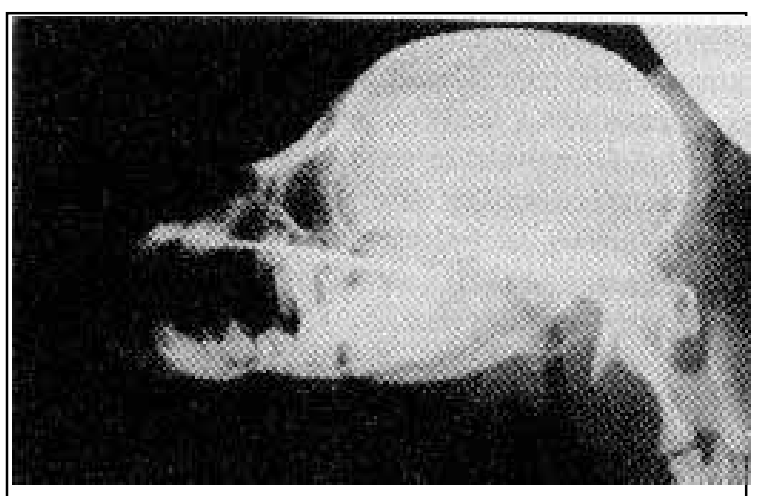

Figura 2 - Radiografia mostrando foco de fratura no ramo da mandíbula, cinco semanas após a ocorrência da fratura. Nota-se ainda linha de fratura.

Um dos cães (3\% dos 30 animais), um Doberman Pinscher, foi reconduzido ao hospital após 12 meses, quando a resina foi removida. Observaram-se, então, retração gengival de $2 \mathrm{~mm}$ na região dos incisivos e caninos inferiores, hemorragia gengival espontânea, mobilidade moderada de todos os incisivos inferiores, coloração quase negra do esmalte desses dentes e do canino (manchamento). O foco da fratura mostrava consolidação óssea pela análise radiográfica, embora houvesse reabsorção óssea horizontal em nível de incisivos, indicando periodontite. A coloração escura sobre o esmalte foi de difícil remoção com raspagem manual, sendo que a mesma somente foi removida, naturalmente, após 3 semanas. Em todos os casos clínicos, o mesmo padrão apresentado no exame clínico pré-remoção da resina, da fase experimental, foi evidenciado: hemorragia gengival espontânea, edema e eritema gengival (caracterizando gengivite), sem sinais de periodontite. Periodontite somente foi diagnosticada nos dois animais citados, a saber: o felino cuja resina foi removida após 4 meses e no cão Doberman Pinscher cuja resina foi removida após 12 meses, que apresentaram retração gengival e reabsorção óssea horizontal.

\section{Aspectos Histológicos}

No espécime sacrificado 24 horas após a aplicação da resina sobre a gengiva, o exame histológico mostrou ulceração em vários pontos do epitélio gengival, com presença na lâmina própria de rica vascularização e células inflamatórias, notadamente polimorfonucleares-neutrófilos e macrófagos, caracterizando processo inflamatório agudo. Este se manteve durante os tempos experimentais de três e sete dias. A partir de 14 dias, e nos tempos subsequientes, os polimorfonuclearesneutrófilos passaram a ser substituídos por células mononucleares, caracterizando processo inflamatório crônico. Estruturas interpretadas como colônias bacterianas foram observadas nos espécimes de 14, 21 e 31 dias. Os sítios da mucosa jugal e da língua mostraram quadros histopatológicos semelhantes, inclusive com pontos de ulceração no tecido epitelial.

\section{DISCUSSÃO}

Nesse experimento, buscou-se utilizar o método de aplicação de resina acrílica nas fraturas do sistema estomatognático de maneira simples, tentando eliminar passos do procedimento, principalmente na fase experimental. Pelo método da resina acrílica para a fixação das fraturas de mandíbula, maxila e separação da sínfise mentoniana, todos os princípios básicos para que se obtenha consolidação óssea foram estabelecidos, concordando com os princípios de MARETTA et al. (1990). Notou-se que $100 \%$ dos animais da fase experimental e $60 \%$ na fase clínica estavam ingerindo alimentação no mesmo dia, após o ato operatório.

Vale lembrar que o método somente é possível de ser aplicado nas fraturas rostrais ao primeiro molar inferior ou quarto pré-molar-superior, uma vez que nas fraturas caudais a esses dentes, não há superfície dental suficiente, ou mesmo ela é inexistente para a fixação da resina acrílica. A literatura, entretanto, não refere, como foi proposto, que a resina possa ser utilizada especificamente nas fraturas rostrais às raízes distais do primeiro molar inferior e quarto molar superior, apenas referindo-se às fraturas rostrais a esses dentes.

Os princípios descritos por MARRETA et al. (1990) estavam todos presentes nos casos clínicos aqui observados após a intervenção cirúrgica. A oclusão dental foi mantida em todos os animais o mais próximo do normal, notada pela oclusão anatômica entre os caninos superior e inferior, pelos incisivos e pelos demais dentes, embora com leve mordida aberta do lado da colocação da resina.

A técnica da resina acrílica mostrou-se muito fácil e de rápida aplicação, o que concorda com as afirmações de COLAHAN \& PASCOE (1983), MULLIGAN (1989) e LUSKIN (1994). Salienta-se a relevância de manter os dentes sem umidade, a qual impede a aderência da resina sobre o esmalte dentário. A utilização de jatos de ar, com seringa tríplice, seringa hipodérmica, oxigênio comprimido, peras de borracha ou secadores de cabelo podem ser eficientes para esse fim.

Deve-se salientar que, para a fase experimental, consumiu-se um maior volume de resina. Todavia, quando comparado aos métodos de placa metálica e fios de aço, os quais necessitam de furadeira manual ou elétrica para a aplicação, o método 
da resina é muito menos oneroso, além de não invadir os tecidos moles e duros da região, concordando com CHAFFE (1978), CHAMBERS (1981), THOLEN (1983), ROSS \& GOLDSTEIN (1986), MULLIGAN (1989), BOJRAB (1990), HARVEY \& EMILY (1993), MARRETTA et al. (1990), HOLMSTROM et al. (1992), SHIPP \& FAHRENKRUG (1992) e EGGER (1993).

O método descrito por ZETNER (1992), de aplicação de pinos de metal na coroa dental para aumentar a retenção da fixação de resina no bloqueio da oclusão, embora eficiente, pode ser substituído pelo método da resina acrílica. Nesse último caso, entretanto, é essencial a técnica precisa de condicionamento ácido do esmalte, para haver maior aderência.

Nos casos em que houve perda de substância óssea, mas ainda foi possível haver contato entre os fragmentos, mantendo a oclusão normal, não se considerou necessária a utilização invasiva de implante de metilmetacrilato, conforme relatou KANGUR et al. (1976).

$\mathrm{Na}$ separação de sínfise mentoniana, o método da resina mostrou-se de fácil aplicação, principalmente se comparado aos métodos descritos por MARRETTA et al. (1990), HOLMSTROM $\boldsymbol{e t}$ al. (1992), SHIPP \& FAHRENKRUG (1992), HARVEY \& EMILY (1993) e CUKJATI (1994), que indicaram cerclagem com fios de aço.

Conforme EGGER (1993) descreve, há grande acúmulo de alimentos e exsudatos no sítio da fratura no pós-operatório, todavia esse fato pode ser contornado pela higienização regular por parte do proprietário. Ao contrário do que descreve o autor, esse fator não interferiu em nenhum caso para a consolidação das fraturas no presente experimento.

Não se utilizou antibiótico, como indica McOWEN (1987) e SHIIPP \& FAHRENKRUG (1992) na maioria dos casos. Administrou-se antibiótico apenas em dois animais que necessitaram de outra intervenção concomitante, a saber: sutura cutânea e osteossíntese de fraturas de ossos longos, devido à possibilidade de infecção pós-cirúrgica naqueles focos, advinda da bacteremia e causada pela manipulação bucal e ao possível fenômeno da anacorese. Também se prescreveu antibióticos a um felino com infecção do trato respiratório anterior.

Não foi utilizada vaselina ou dique de cera sobre os tecidos moles da região, conforme indicam MULLIGAN (1989), HOLMSTRON et al. (1992) e SHIPP \& FAHRENKRUG (1992), uma vez que se adotou, como método na fase clínica, não contatar a resina a esses tecidos. Além disso, utilizou-se o método de mistura entre o polímero e o monômero em recipiente de vidro e não diretamente sobre os dentes. Na fase experimental, foi objetivo haver contato entre a resina e os tecidos moles, principalmente com a gengiva, para se proceder à análise histológica. Entretanto, aconselha-se a aplicação de um protetor, como vaselina ou cera, por veterinários ainda com pouca prática com a manipulação da resina, para minimizar os riscos de lesões ulcerativas sobre o tecido periodontal.

Concorda-se com HOLMSTROM et al. (1992), uma vez que as lesões ulcerativas nos tecidos moles, principalmente na gengiva, regrediram em poucos dias após a remoção da resina nos animais da fase clínica. Pela análise histológica, na fase experimental, que revelou primordialmente um quadro de ulceração, acredita-se que as lesões sejam decorrentes da reação exotérmica da resina, dificuldade de remoção natural da placa bacteriana, das forças mecânicas da mastigação, e pelo contato das mucosas com a resina acrílica no pós-operatório.

Não se pode comparar os aspectos histológicos deste experimento com outros trabalhos, uma vez que não há relatos na literatura da análise histológica, após a aplicação da resina acrílica nesse tipo de intervenção cirúrgica. Notadamente, os processos de inflamação gengival foram clássicos, causados nas primeiras 24 horas, provavelmente pela reação térmica e, posteriormente, pela placa bacteriana.

Assim como descreveram SHIPP \& FAHRENKRUG (1993), os dentes nos focos de fratura, mas que ainda mantinham sustentação por uma das raízes, foram preservados e utilizados como pontos de retenção para a resina, principalmente nos animais com fraturas patológicas. Nesses casos, é imprescindível a raspagem de cálculos e placa dental, acompanhada de vigoroso aplainamento radicular, uma vez que o epitélio juncional viável pode ser readerido ao cemento previamente raspado.

Embora os exames radiográficos sejam úteis nesse tipo de fratura, em muitos casos apenas o exame clínico direto pode ser conclusivo na escolha do tratamento, com base na palpação, quando se pode ter uma idéia tridimensional do tipo de fratura e da mobilidade dos fragmentos ósseos. Contudo, aconselha-se a realização de exame radiográfico, mesmo nos casos mais simples, em decorrência da possibilidade de não-união dos fragmentos e outras complicações (SHIPP \& FAHRENKRUG, 1992), assim oferecendo radiografias comparativas em diferentes tempos de evolução. A não-união não ocorreu em nenhum dos casos tratados. Novos estudos devem ser realizados para se compararem os achados radiográficos de consolidação nas fraturas do sistema estomatognático, após a fixação dos fragmentos, uma vez que em 19 animais (63\% dos 
30 totais) não houve sinais radiográficos de consolidação óssea na linha de fratura entre 28 e 35 dias de evolução, nos cães da fase clínica, embora, mesmo assim, a resina tenha sido removida. Ao que pareceu, os sinais de consolidação óssea ao exame radiográfico são tardios nesse tipo de fratura, principalmente na mandíbula, provavelmente pela estabilização total dos fragmentos ósseos. Não se utilizou a técnica de condicionamento ácido na fase experimental, pois tentou-se estabelecer um método mais rápido, eliminando passos. Todavia, embora tenha havido fixação da resina sobre os dentes, foi necessário usar um volume maior de resina para obter-se a fixação mecânico-retentiva, não relacionada à união com o esmalte dental. Isso acarretou em maior contato do polimetilmetacrilato com os tecidos moles da boca, principalmente gengiva, lábios e língua, levando à ulceração. $\mathrm{O}$ uso da resina sem o condicionamento ácido é crítico, em vista de que não deve haver qualquer umidade entre superfície dental e a resina, o que impede a aderência. Embora se tenha constatado, pela fase experimental, que é possível eliminar a utilização de condicionamento ácido do esmalte, aconselha-se seu uso previamente à aplicação da resina acrílica, a fim de aumentar a retenção com um volume mínimo do metilmetacrilato. Essa foi a técnica assim escolhida para a fase clínica.

\section{CONCLUSÃO}

O método da resina acrílica pode ser utilizado nas fraturas rostrais às raízes distais do primeiro molar inferior e do quarto pré-molar superior, bem como na separação da sínfise mentoniana;

o contato da resina acrílica com os tecidos moles da cavidade oral conduz à ulceração e gengivite, clínica e histológica;

a resina acrílica pode ser usada sem a aplicação do condicionamento ácido do esmalte, desde que o volume utilizado para conseguir-se adequada retenção mecânica seja maior;

o método da resina acrílica é barato, não invasivo, rápido de ser aplicado e permite que forças de oclusão sejam aplicadas sobre a resina, no pós operatório, sem que essa sofra rompimento.

\section{FONTES DE AQUISIÇÃO}

a - Resina acrílica Jet Acrílico Autopolimerizante - Artigos Odontológicos Clássico Ltda., SP.

b - Pedigree - Éffem, Mogi Mirim, SP.

c - Fio de poligalactina 910 2-0, 3-0, e 4-0 Vycril - Ethicon, São José dos Campos, SP.

\section{REFERÊNCIAS BIBLIOGRÁFICAS}

BOJRAB, J.M. Current techniques in small animal surgery. Philadelphia : Lea \& Febiger, 1991. 950p.
CHAFFE, V.W. Veterinary medicine small animal clinics. Philadelphia : Saunders. 1978. Cap.73: A technique for fixation of bilateral mandibular fractures caudal to the canine teeth in the dog: p.907-909.

CHAMBERS, J.N. Principles of management of the mandibular fracture in dogs and cats. Journal Orthodontics, v.2, p.2636,1981 .

COLAHAN, P.T., PASCOE, J.R. Stabilization of equine and bovine mandibular fracture using acrylic splint. J Am Vet Med Assoc, v.182, n.10, p.1117-1119, 1983.

CUKJATI, J.F. Treatment of chronic mandibular symphyseal rupture with a compressive device. In: WORLD VETERINARY DENTAL CONGRESS, 1994, Philadelphia, USA. Proceedings... Philadelphia : American Veterinary Dental College, 1994. 172p. p.62-63.

DAUTHEVILlE, P., BARRAIRON, E. Odontostomatologie veterinaire. Paris : Maloine, 1985. 210p.

EGGER, E.L. Skull and mandibular fractures. In: SLATER, D. Textbook of small animal surgery. 2. ed. Philadelphia : Saunders, 1993. V.2, p.1910-1921.

EISENMENGER, E., ZETNER, K. Veterinary dentistry. Philadelphia : Lea \& Febiger, 1985. 165p.

GIOSO, M.A. Odontologia veterinária para o clínico de pequenos animais. 3. ed. São Paulo : FMVZ-USP, 1994. 51p. (publicação interna).

GIOSO, M.A., CORREA, H.L., VENTURINI, M.A.F.A. Study of enamel micromorphology and resistance to separation of composite restorations from teeth of dogs. In: FOURTH WORLD VETERINARY DENTAL CONGRESS, 1995. Vancouver, Canada. Proceedings... Vancouver : American Veterinary Dental College, 1995. 181p. p.94.

HARVEY, C.E., EMILY, P. Small animal dentistry. St. Louis : Mosby, 1993. 413p.

HARVEY, C.E., NEWTON, C.D., SCHWARTS, A. Small animal surgery. Houston : Lippincott, 1990. 68p.

HOLMSTROM, S.E., FROST, P., GAMMON, R.L. Veterinary dental techniques for the small animal practitioners. Philadelphia : Saunders, 1992. 430p.

KANGUR, T.T., TOLMAN, D.E., JOWSEY, J. The use of methylmetacrilate in the fixation of mandibular fractures in dogs: experimental results. Oral Surg Oral Med Oral Pathology, v.41, p.578, 1976.

LUSKIN, I. Fabrication of acrylic palatal inclined plane to correct base narrow and other conditions. In: WORLD VETERINARY DENTAL CONGRESS, 1994, Philadelphia, USA. Proceedings... Philadelphia : American Veterinary Dental College, 1994. 172p. p.153-155.

MARRETTA, S.M., SCHRADER, S.C., MATTHIESEN, D.T. Problems associated with the management and treatment of jaw fractures. In: MARRETTA, S.M. Problems in veterinary medicine. Dentistry. Philadelphia : Lippincott, 1990. Cap.10, p.220-247.

McOWEN, J.S. Intra-oral dental acrylic splint for mandibular fracture: a case report. Companion Animal Pract, v.1, p.17, 1987. 
MULLIGAN, T.W. Management of the mandibule and maxilla fractures. In: AMERICAN ANIMAL HOSPITAL ASSOCIATION, 1989, St. Louis, USA. Proceedings... St. Louis : Dental Seminar, 1989. 352p. p.149-177.

ROSS, D.L., GOLDSTEIN, G.S. Oral surgery. Basic techniques. Veterinary Clinics of North America: Small Animal Practice, v.16, n.5, p.1251-1263, 1986.

SHIPP, A.D., FAHRENKRUG, P. Practitioner's guide to veterinary dentistry. Glendale : Dr. Shipp's Laboratory, 1992. 273p.
THOLEN, M.A. Concepts in veterinary dentistry. Kansas : Vet.Med, 1983. 185p.

WIGGS, R.B., LOBPRISE, H.B. Veterinary dentistry. Principles and practice. Houston : Lippincott-Raven, 1997. p.748.

ZETNER, K. Treatment of jaw fractures in small animals with parapulpar pin composite bridges. Veterinary Clinics of North America: Small Animal Practice, v.22, n.6, p.1461-1467, 1992.

Ciência Rural, v. 31, n. 2, 2001. 